\title{
Students' Reactions to Natural and Physical Phenomena: Documenting Wonder and Engagement with Science Content Knowledge
}

\author{
Yannis Hadzigeorgiou ${ }^{1 *}$ \\ 1 University of The Aegean, GREECE \\ *Corresponding Author: hadzigeo@ rhodes.aegean.gr
}

Citation: Hadzigeorgiou, Y. (2022). Students' reactions to natural and physical phenomena: documenting wonder and engagement with science content knowledge. Interdisciplinary Journal of Environmental and Science Education, $18(1), \mathrm{e} 2261$. https://doi.org/10.21601/ijese/11340

\begin{tabular}{|c|c|}
\hline ARTICLE INFO & ABSTRACT \\
\hline $\begin{array}{l}\text { Accepted: } \\
6 \text { September } 2021\end{array}$ & $\begin{array}{l}\text { The purpose of this study was twofold: First, to document how students react to various natural and } \\
\text { physical phenomena, and second, whether observation of these phenomena can foster students' } \\
\text { sense of wonder and their engagement with science content knowledge through self-directed } \\
\text { inquiry. The sample consisted of forty-six 11th and 12th grade students from a variety of schools } \\
\text { located in the wider metropolitan area of a European capital. They were all volunteers, who kept a } \\
\text { journal, in which they wrote their 'genuine' feelings and thoughts about nine specific phenomena, } \\
\text { when they first looked at them (first reaction), and during their investigation, if they did choose to } \\
\text { pursue an investigation, in order to understand and/or learn more about them. Those phenomena } \\
\text { were given to the students in the form of a photograph and a short videoclip. The students were given } \\
\text { the option not to make an entry (i.e., write anything in their journals) if they thought the phenomenon } \\
\text { was not worthy of their attention. A content analysis of students' journal entries provided evidence } \\
\text { for three major categories/reactions to natural phenomena, namely, (a) "admiration/perception of } \\
\text { beauty", (b) "intellectual curiosity" and (c) "admiration mingled with intellectual curiosity". For some } \\
\text { students, although a small percentage of the sample, the above categories could be considered } \\
\text { student 'profiles', given that those students consistently expressed "admiration" or "intellectual } \\
\text { curiosity" or "admiration mixed with curiosity" across all situations/phenomena. However, most } \\
\text { students' reactions and thoughts varied according to the situation/phenomenon they observed. All } \\
\text { students, with the exception of those whose reactions fell within the first category, were engaged in } \\
\text { self-directed inquiry for the purpose of understanding, and in some cases even learn more about, } \\
\text { natural and physical phenomena. The implications of these results for science education are also } \\
\text { discussed. }\end{array}$ \\
\hline
\end{tabular}

Keywords: wonder, curiosity, admiration, engagement, beauty, science, understanding

\section{INTRODUCTION}

The importance of inquiry-based learning in science education is well established (e.g., Krajcik, Mamlok, \& Hug, 2001; National Research Council, 2007; Riga et al., 2017). However, while the role of questions in students' inquiry is explicitly acknowledged (e.g., Hynes-Berry \& Berry, 2014), the role specifically of observation of natural and physical phenomena in initiating and fostering student inquiry is either taken for granted or not explicitly discussed. Even though the various phenomena can be sources of students' curiosity and wonder, both of which can initiate and sustain scientific inquiry, starting form students' observation may not be considered pedagogically appropriate for a number of reasons (e.g., the critique of the inductivist epistemology, the constructivist arguments about the passivity inherent in the process of observation). Philosopher Karl Popper convincingly argued that "the vital first step towards understanding a theory is to understand the problem situation in which it arises" (Popper, 1972, p. 182),

Copyright (C) 2022 by Author/s and Licensed by Veritas Publications Ltd., UK. This is an open access article distributed under the Creative Commons Attribution License which permits unrestricted use, distribution, and reproduction in any medium, provided the original work is properly cited. 
which implies that observation can only help students understand a science idea if it (observation) makes them aware of a problem situation that gives rise to that idea. Moreover, observation, in and of itself, may not be sufficient to make students curious and evoke in them a sense of wonder. In fact, in the case of very young students, one should be reminded of what Rachel Carson had pointed out, in her The Sense of Wonder, namely, keeping alive a child's inborn sense of wonder requires the companionship of at least one adult who must share this sense of wonder with the child, and thus rediscover with the child the mystery, the joy and the excitement of the natural world (Carson 1965).

Yet, observation does play a significant role in scientific inquiry. While questions, problems, experimentation for the purpose of answering those questions and solving problems, and also the use of tools for gathering, analyzing and communicating data are considered central to scientific inquiry, the latter is "a multifaceted activity, that also involves "making observations; posing questions; examining books and other sources of information" (NRC, 1996, p. 23). Starting, however, from the observation of phenomena is quite crucial from a phenomenological perspective, which gives primacy to "the aesthetic dimension of knowledge formation" and involves "a careful and exact attention to all the qualities inherent in sense experience" (Dahlin, 2001, p. 130). Such a perspective is not only about appreciating the beauty of natural phenomena but also about understanding them. Thus, the romantic idea of the "phenomenological richness" of nature is an idea that can be reclaimed in science education if engagement with science - its processes and content knowledge is a goal (Hadzigeorgiou \& Schulz, 2014). A romantic idea, central to the study of nature, is the experience of wonder.

It is true that curiosity and wonder are the sine qua non of science (e.g., Ball, 2013; De Cruz, 2020; Lindholm, 2018), and therefore a good science education should foster them both. The fact that both curiosity and wonder are associated with feelings of joy, excitement, and intellectual satisfaction (Kashdan, 2019; see also Bazhydai \& Westermann, 2020) can make them central to the teaching/learning process, even though such expressions or instructional approaches to school science, as 'fun science', 'inquiry science', and 'creative science', do not necessarily entail the experience of wonder (Hadzigeorgiou, 2016). However, the experience of wonder is difficult to conceptualize given that wonder becomes manifest in a variety of "guises", and the notion of wonder itself, more often than not, is conflated and used interchangeably with that of intellectual (or epistemic) curiosity (Hadzigeorgiou, 2014, 2020; Gilbert, 2020; Gilbert \& Byers, 2017; Schinkel, 2017, 2020). But its role in fostering scientific inquiry is well recognized, as is the fact that it can have a variety of sources (Hadzigeorgiou, 2016, 2020). One such source is the various natural and physical phenomena that are or could be part of the science curriculum. This study is an attempt to investigate, through content/thematic analysis, students' own feelings and thoughts about various phenomena that have the potential to evoke in them a sense of wonder, and the extent to which such wonder can foster the search for information and investigation for the purpose of understanding a phenomenon. A conceptual clarification, however, of the experience of wonder is imperative.

\section{THEORETICAL BACKGROUND}

Educational theorist Kieran Egan, in criticizing the contribution of educational research to our knowledge of what 'learning' and 'development' really involve, argued that "methodological sophistication cannot compensate for lack of conceptual clarity (Egan, 2005, p. 39). No doubt, such clarity is of crucial importance in the case in which the experience of wonder is studied, given its complex and elusive nature. Anything that is unexpected, surprising, extraordinary, perplexing, astonishing and amazing - from natural phenomena and nature's artistic creations to human achievements of various kinds - can be a source of wonder. It can often be a wide-eyed and jawdropping experience, which leaves one befuddled and in confusion, while its emotional intensity can also vary, depending upon a variety of factors (e.g., source of wonder, personal worldview). But while the experience of wonder involves surprise, astonishment, admiration, bewildered curiosity, perplexity and confusion, this experience cannot be reduced to any one of these elements. Moreover, because wonder is evoked, literally anything can be a source of wonder, including even familiar and ordinary entities and phenomena.

A misunderstanding of the nature of wonder, especially in the context of education, may very well be one of the reasons why its value has not been fully recognized (Glaveanu, 2020; Hadzigeorgiou, 2016; Schinkel, 2020). While, for example, the affective dimension of the experience of wonder is widely acknowledged, its cognitive dimension is not. On the other hand, taking the value of wonder for granted, and therefore accepting that there is no need to talk about, let alone explicate, its nature, does not help us understand its implications for the teaching/learning process. Even though a philosophical analysis of wonder is beyond the scope of this paper, a 
discussion of the various senses or 'guises' of wonder, and the awareness that accompanies its experience, can shed some light on its complex and elusive nature. Such discussion can help interpret the results of the present study and point to certain implications for the teaching/learning process in the context of school science education.

\section{"Senses" of Wonder}

Wonder has a long history in philosophical thought. For Plato "Wonder ('thaumazein') is the beginning of philosophy" (Plato, Theaetetus, 155d, in Burnyeat, 1990), something with which his student Aristotle concurred: "Men were first led to philosophy, as indeed they are today, by wonder" (Aristotle, 2002, Metaphysics I, 982b). While for both Plato and Aristotle wonder was explicitly associated with puzzlement and perplexity, there is a subtle difference between the two philosophers. For Plato, wonder was directly linked to "aporia", meaning, literally, no path to follow, and hence to an 'intellectual impasse', which signals the limits of one's knowledge and hence one's ignorance. The intellectual impasse had its source in contradictions and paradoxes that arose in the process of understanding the true meaning of taken-for-granted ideas such as good, virtue, morality, etc. As Theaetetus admits: "Yes, Socrates, and I am amazed when I think of [these questions and contradictions]; by the Gods I am! And I want to know what on earth they mean" (Plato, Theaetatus, 155d). For Aristotle though wonder was associated not only with perplexities and "aporias" about taken-for-granted ideas, but also with questions arising from the observation of natural phenomena: "It is through wonder that men now begin and originally began to philosophize; wondering in the first place at obvious perplexities, and then by gradual progression raising questions about the greater matters too, e.g. about the changes of the moon and of the sun, about the stars and about the origin of the universe. Now he who wonders and is perplexed feels that he is ignorant" (Aristotle, 2002, Metaphysics I, 982b).

Thus, while for Plato wonder was the source of perplexity, bewilderment and confusion, and its purpose was to exercise the human intellect, for Aristotle wonder was the means of seeking answers to questions that arose both in daily life (i.e., practical reasoning, practical wisdom) and from observing and trying to understand the natural world (i.e., the origin of science).In short, for Aristotle wonder was the source of all intellectual inquiry (Lloyd, 2018). What should be noted though is that central to both senses of wonder was an aesthetic dimension, and specifically a feeling of admiration. Marcel (1963), in fact, had argued that the "thaumazein", that is, the wonder of the Ancient Greeks lies on the borderline between wonderment and admiration. However, it could be argued that admiration appears more salient in Aristotle's wonder, given that, in contrast to Plato's (or Socratic) wonder, which is evoked by paradoxes and contradictions in thought, Aristotle's wonder is more akin to awe evoked by natural phenomena.

Even though Aristotle's notion of wonder took on the 'guise' of intellectual curiosity in the form of questions about the origin of natural phenomena, the component of admiration was always present. One should bear in mind that the word 'curiosity', at the time of Aristotle had bad connotations (i.e., it was associated with the activity of prying into people's personal affairs), so 'thaumazein' was the word associated with what we call today intellectual or epistemic curiosity (Ball, 2013), which, as was said, was on the borderline between wonderment and admiration. So, the 'guise' of intellectual or epistemic curiosity was in the form of wonderment that led to questions and hence to an inquiry into the origin of the various natural phenomena. However, wonderment was always accompanied by admiration. According to Aristotle, for example, one can indeed become very curious about the origin of perfect hexagonal cylinders that can be found in several places on the planet, but, at the same time, experience a sense of wonder (i.e., admiration) at that natural phenomenon. In fact, the admiration may very well remain even after one inquires and learns about how liquid magma helped shape those cylinders. This is something with which A.N. Whitehead (1938) concurred: philosophy, not only begins in wonder, but also ends in wonder.

The multiplicity of views regarding wonder notwithstanding, the two notions, that is, "intellectual curiosity" and "admiration" can describe the experience of wonder while pointing to its dualistic nature: On the one hand, a sense of wonder involves an "active questioning", and hence to a desire to know more and to understand, and on the other hand a "passive contemplation". The former is identified with intellectual curiosity while the latter with an admiration of the world and a response to something mysterious beyond one's comprehension, but worthy, nevertheless of one's attention (Schinkel, 2017). The former can lead to an analysis, through an investigation, the latter focuses on wholeness. This dualistic approach though is something that may raise objections. For example, Taylor (1998) identified wonder with "admiratio". "Wonder is poetic and is content to view things in their wholeness and full context [. . . curiosity is not wonder, the former being the itch to take apart, the latter to gaze on things as they are" (Taylor, 1998, p. 169). Philosopher Genevieve Loyd, however, while 
recognizing specifically an "admiring wonder" (Lloyd, 2018, p. 135), also discusses the importance of wonderment, which should not be identified only with the Romantic notion of the sublime (i.e., feelings associated with the breathtaking beauty of natural landscapes). For it is true that although in the Romantic period many scientific discoveries were made, and exploration of the unknown was central to Romantic science, wonder, by and large, was inspired by awe and universal mystery (Hadzigeorgiou \& Schulz, 2014).

The wonder of science, however, which both Feynman $(1969,1989)$ and Dawkins (1998) talked about, is explicitly associated with the beauty of scientific ideas, and hence with a wonder-at state of mind. This wonder, as empirical evidence suggests, has indeed an aesthetic dimension, as it involves admiration for the scientific ideas themselves or the scientists who propounded those ideas (Hadzigeorgiou, 2012; Hadzigeorgiou \& Garganourakis, 2010). While the experience of wonder associated with a wonder-about state of mind cannot be ruled out in the case of the beauty of scientific ideas, what is more salient in the case of scientific ideas is the admiration for such ideas, and hence a wonder-at state of mind. Yet, such sense of wonder may very well be differentiated from the wonder that 'strikes', as when one observes an entity or a phenomenon that is beautiful, amazing, and perhaps incredible. The wonder experienced, for example, when one learns that "we are all stardust" Carl Sagan's famous example - or that light is indeed invisible, can be differentiated from the wonder experienced when one observes, for example, a double rainbow. Even though both the idea that "we are all stardust" and a double rainbow can 'strike', the former presupposes an awareness, which can be absent when one observes a double rainbow.

Stolberg's (2008) findings from his study with inservice teachers pointed to a differentiation between "physical wonder" (which is induced by interaction with natural entities and phenomena), "personal wonder" (which is induced by interaction with human beings and/or by their achievements), and "metaphysical wonder" (which is induced by any kind of interaction, that leads to a change in perspective). However, there is empirical evidence form a study with high-school students that a sense of wonder at and about science ideas and natural phenomena can also lead to a shift in perspective, namely, a change in the way some students view such phenomena and science as a school subject (Hadzigeorgiou, 2012). Similar results have also been reported in the case of preschoolers, who learned about the importance of trees (Hadzigeorgiou et al., 2011). Such findings point to an overlap between different categorizations or senses of wonder. While the differentiation between a passive or contemplative sense of wonder (i.e., the wonder-at state of mind) and an active sense (i.e., the wonderabout state of mind) in the form of intellectual curiosity may be useful to understand the various 'guises' of wonder, the notion of "thaumazein" points to the interrelationship or an overlap between the two senses. From such a perspective, the view that there should be a differentiation between "wonder in the sense of curiosity" and "wonder in the sense of the magical, miraculous and incomprehensible", which "is like a narcotic and destroys curiosity and anesthetizes the intellect" (Silverman, 1989, p. 44) should be given more serious thought and perhaps reconsidered.

For it is a fact that, apart from the educational significance of passive wonder (Schinkel, 2017, 2020), the wonder of ideas (e.g., Dawkins' sense of wonder) should not be seen simply as a response to something incomprehensible, even though such wonder makes more salient the passive sense of wonder. Such wonder is evoked by the very ideas of science that are indeed admirable and deserve one's full attention and admiration, and can enhance (i.e., add more wonder to) one's sense of wonder at the sight of a phenomenon through both a wonder-about state of mind (i.e., possibility thinking) and a wonderat state of mind. It is for this reason that Nobel laureate Richard Feynman said that knowledge of science adds to the beauty of a flower, as the latter is perceived by an artist: "There are all kinds of interesting questions that come from a knowledge of science, which only adds to the excitement and mystery and awe of a flower. It only adds. (Feynman, 1989, p. 11).

There is a question though when one observes a phenomenon and simply wonders at that phenomenon, because the latter is something astonishing, unexpected, even extraordinary, and perhaps incomprehensible: Is one, without the background knowledge of science, simply puzzled and paralyzed, and hence unable to wonder about that phenomenon in order to understand it? This, in actual fact, is one of the research questions that this study attempted to answer, as discussed in the context and methods section. Nevertheless, from a theoretical perspective, if there is an overlap between wonderment and admiration, there is a possibility that a wonder-at state of mind leads to a wonderabout state of mind, which can be either associated or identified with intellectual curiosity, and hence with questions that aim at comprehension. But this can be better understood if the difference between curiosity and wonder is considered. 
What should be pointed out though is that while there is a multiplicity of what can be called forms, senses or even "guises" or "faces" of wonder (Hadzigeorgiou, 2014, 2016; Schinkel, 2017), the distinction between the two senses "wonder-at" and "wonder-about" is central to our understanding of wonder. While the former, as was said, is considered passive, and involves an admiration of something (e.g., an entity, a phenomenon, an idea that "strikes"), and/or the response to something mysterious, the latter is "active" and could be identified with intellectual curiosity (i.e., a drive to explore and understand). However, such distinction does not mean that there can be no overlapping between the two. For example, one wonders at the beauty of Niagara Falls and at the power of the falling water, but also one wonders at the fact that there are more water molecules in a glass of water than there are glasses of water which contain the water of the whole Mediterranean Sea. It is very likely that the wonder evoked by the immensity of the number of water molecules in a glass of water leaves one amazed and passive. But it is also likely that this kind of wonder makes one intellectual curious to understand such immensity by associating it with Avogadro's number (Hadzigeorgiou, 2012).

Another issue relating to the various senses of wonder, as was discussed thus far, is the variety of terms used to describe wonder. For example, a 'wonder-at' sense of wonder has been identified with passivity, contemplation, even incomprehensibility, according to the literature on wonder (Gilbert \& Byers, 2017; Hadzigeorgiou, 2016, 2020; Schinkel, 2017), and hence the terms 'contemplative', 'passive', or even "deep wonder" (Schinkel, 2020).

\section{The Relationship between Wonder and Curiosity}

If one considers the passive/contemplative sense of wonder, its difference from curiosity is easy to understand: "Curiosity belongs to the scientific impulse and would strive to dominate nature; whereas wonder is poetic and is content to view things in their wholeness and full context (Taylor, 1998 , p. 169). Such a view of wonder had been expressed by Martin Heidegger in his Time and Being: "Curiosity has nothing to do with observing entities and marveling at them [...] once curiosity obtains sight of anything, it already looks away to what is coming next" (Heidegger, 2008, p. 216, p. 398). Such an association between wonder and beauty was made by Richard Feynman, whose approach to nature is a case in point. Even though he stressed the role and value of intellectual curiosity in doing science (see Feynman, 2015, pp.165-183), Feynman did talk very often about his sense amazement, mystery, even awe and admiration. With regard to gravity, for example, he said that the first amazing fact about gravitation is that the ratio of inertial mass to gravitational mass is constant whenever we have checked it. And the second amazing thing about gravitation is how weak it is. And, with regard to scientific laws, he did point out that they end "in mystery and awe, lost at the edge in uncertainty, but they appear to be so deep and so impressive" (Feynman, 2015, p.119). His sense of wonder at the universe can be seen in the following passage:

It doesn't seem to me that this fantastically marvelous universe, this tremendous range of time and space and different kinds of animals, and all the different planets, and all these atoms with their motions, and so on, all this complicated thing can merely be a stage so that God can watch human beings struggle for good and evil -which is the view that religion has. The stage is too big for the drama. (Feynman, 2015, p. 112)

Apparently, such a differentiation between curiosity and wonder, points to the identification of the latter with a wonder-at state of mind, thus implying that the wonder-about sense of wonder must be identical with intellectual curiosity. This claim can be supported by Dewey's (1998) distinction among three kinds of curiosity, namely, organic, social, and intellectual. Only the last kind is associated with "genuine consciousness of rational thought" (p. 38), and thus with an awareness of the limits of one's knowledge and understanding (Hadzigeorgiou, 2012, 2016) and also with a desire to understand and a quest for knowledge about natural phenomena (Krapp \& Prenzel, 2011).

If, on the other hand, one considers the activequestioning sense of wonder, its difference form curiosity is not easy to identify. For there is a great overlap between the two, and that overlapping refers to people's desire to fill knowledge gaps and to understand. However, there is a subtle difference between wonder and intellectual curiosity in the sense is that admiration, possibility thinking and a 'felt awareness' may also be absent from intellectual curiosity.

Two examples can help illustrate this difference. A child is intellectually curious about - and we often say that he/she wonders about - what the surface of the moon looks like from close-up. This can be simply intellectual curiosity, and its purpose is to fill a knowledge gap by obtaining some pieces of information. Another child though who sees a jar with various liquids, one on top of the other, may very well wonder at and about what he or she observes. This child may wonder at the sight of the jar (i.e., upon 
seeing something not only unexpected but also beautiful and admirable) and may also wonder about what he/she observes. His/her wonder-about state of mind may be identified with intellectual curiosity but may also be identified with possibility thinking. Indeed, the child may very well wonder about how what he or she sees is possible in the first place. Moreover, the child is more likely to experience a sense of wonder even after he/she inquires and learns how she/he herself/himself can actually create all those layers. This is not to say that what the first child observes cannot incite a sense of wonder at and about the moon. It is likely that, once the child observes craters of various sizes, and satisfies his/her curiosity, he/she begins to wonder at such an unexpected picture of the moon surface and may also wonder about where all those craters came from, and why there are so many of them on the moon. He/she may also wonder at and about the fact that some astronauts' footsteps can be easily viewed even though they were left there several decades ago. However, such wonderment differs from his/her initial curiosity about what the surface of the moon looks like.

Intellectual curiosity, however, may also be differentiated from wonderment in the sense that the former does not necessarily involve an intellectual struggle that results from an "aporia". For example, being intellectually curious about what the surface of the moon looks like or about the length of the biggest whale, is very different form the intellectual struggle one experiences due to something paradoxical or contradictory: why do veins appear blue although the blood in them has a red colour? While a child who becomes aware of such a contradiction will try to find the answer to this question and is intellectual curious to understand what is going on with human physiology, the source of his/her curiosity is his/her wonderment in the form of an aporia. By the same token, a student may very well wonder when he/she expresses an aporia about the surface of the moon: "If we know that craters are formed when an asteroid or meteor hits the surface of a celestial body, why are there very few craters on the surface of the Earth, although the latter is more likely to be hit by asteroids or meteors due its bigger surface?" Such aporias are 'authentic' wonderment questions that focus on comprehension and not simply on information.

The importance of wonderment, in the form of an aporia, as the source of intellectual curiosity, can be illustrated by MIT physicist Max Tegmark's aporia: "If we know that subatomic particles can be in different places at the same time, then why can't people, who are made of such particles, as well?" This, in fact, was an aporia that played a major role in Max Tegmark's decision to become a physicist (Tegmark, 2015).
Tegmark's intellectual curiosity about why people cannot be in different places at the same time had its source in a contradiction, in a cognitive conflict, that is. While it appears that Max Tegmark, as young high school student, was intellectually curious about the possibility of being simultaneously in different places, because he simply wanted to fill a knowledge gap, the source of his intellectual curiosity was his "aporia". However, what this specific example shows is that Tegmark became aware that his knowledge, at the time, was incomplete (or perhaps erroneous). This dimension of awareness, which represents the cognitive dimension of wonder, can be also absent form curiosity. Even though both curiosity and wonder are associated with knowledge gaps, it is latter that always involve an awareness that one's knowledge is incomplete or mistaken, even an awareness that some phenomena exist at all (Hadzigeorgiou, 2020).

In regard to the role of wonderment in the form of an aporia, Opdal's (2001) analysis also points to a subtle difference between curiosity and wonder: The former is a motive for an exploration within a definite and accepted frame (i.e., system of thought); the latter is about doubt about the frame itself. For example, if one were to consider the everyday frame of thinking (i.e., motion always implies a force), one can be curious about how much force is required to pull a heavy box across a surface of ice, when the frictional force is very low. However, one begins to wonder at and about the idea that there can be uniform straight-line motion of an object in the absence of a net force. In this case one begins to doubt about one's frame of thinking, to use Opdal's (2001) term. It is quite evident that it is wonder rather than curiosity that is transformative, that is, make one see things in a new light.

However, the difference between intellectual curiosity and wonder can be seen in the context of creativity too. As Glavenau (2019) points out, the experience of wonder is often linked to acts of creativity, both historical and mundane, from big breakthroughs in science to the everyday activities and discoveries of children at play. Thus, according to his analysis, it is wonder, not curiosity, that fosters creativity through possibility thinking, that is, "experiencing what is present (the here and now) through the lenses of what is absent (the not-yethere)". Such a possibility of multiple perspectives is the result of the experience of wonder, and there is some empirical evidence with grade 9 students which documents it in the context of science education (Hadzigeorgiou, 2012). Even in the case in which students find an idea paradoxical and contradictory (e.g., light is invisible), and are intellectually curious to learn whether and why this is a true idea, they 
wonder about how such an idea is possible in the first place. In fact, what is important to point out here is that after they learned, through a simple demonstration experiment, that light is indeed invisible (i.e., we see only its source and what light 'hits') they experienced a sense of wonder at and about that idea nonetheless (Hadzigeorgiou, 2012).

In discussing the relationship between intellectual curiosity and wonder, two things should be made clear. First, the active sense of wonder (i.e., when one wonders about something) may or may not be identified with intellectual curiosity (even though such an active sense has been identified with intellectual curiosity in the literature, see Silverman, 1989). For example, one wonders about how to solve a problem (i.e., how to overcome an obstacle) without being curious at all. However, one may very well wonder about how it is possible in a wave swinger at an amusement park that both loaded and empty chairs to form the same angle to the vertical (Hadzigeorgiou, 2016). These two examples illustrate not only the relationship between intellectual curiosity and wonder, but also the difficulty one has to conceptualize latter. And second, an 'aporia', as form or guise of wonder, should not be conflated with intellectual curiosity.

An "aporia" (i.e., a tool that Socrates used with his interlocutors) refers to one's awareness of one's ignorance (i.e., one's limits of current knowledge and understanding), resulting primarily from contradictions in thought (that point to one's limited or even erroneous knowledge). Such contradictions lead to an intellectual struggle for the purpose of understanding a phenomenon (e.g., how is it possible that both heavy and light objects fall to the ground simultaneously?) or an idea (e.g., If we know that subatomic particles can be in different places at the same time, then why can't people, who are made of such particles, as well?". On the other hand, intellectual curiosity refers to the drive to know something. However, that drive may very well fill a knowledge gap through the acquisition of information (e.g., a child wants to know why the sky is always blue during sunny days), or, there can be cases in which that drive has its source in one's aporia (e.g., how is it possible that both heavy and light objects fall to ground simultaneously?), and hence in one's intellectual struggle to understand.

In light of these subtle differences between a wonder-about state of mind and intellectual curiosity, the issue that is raised in the context of science education is whether students really wonder at and about the various phenomena, despite the fact that it is not an easy task for a science educator, let alone a science teacher, to know when a student wonders about something or simply is intellectually curious about something. Simply filling knowledge gaps cannot, and should not, be seen as the criterion whereby one judges the difference between curiosity and wonder, even though both are central to science and science education. In this study, a wonder-about state of mind has been categorized as intellectual curiosity that aims at comprehension (and at the acquisition of information for the purpose to understand a phenomenon).

\section{CONTEXT AND METHODS}

The sample used in this study was a convenient sample, in the sense that the participants were all volunteers, which consisted of 46 students, from a variety of schools located in the wider metropolitan area of a European capital. Such a sample was considered useful for the purpose of the present research because it included students from a variety of backgrounds and interests but also a limitation to interpret the results. Indeed, the fact that all students were all volunteers may very well have had an effect on the stability of data collected through the students' journals (e.g., a simple random sampling procedure may have resulted in different data as far as the number of students who became engaged with the phenomena is concerned). Moreover, the journal, as an instrument used for the collection of data may also have had an effect on the reliability of data (Drew, Hardman \& Hosp 2009). However, the use of two external researchers for the analysis of the data helped minimize this problem. What should be pointed out though is that the convenient sample used in the present study was useful, in the sense that it shed light on how students react to the various natural and physical phenomena. In other words, while the quantitative data of the study (e.g., number of students who decided to become involved with the various phenomena, number of phenomena that were most interesting to students), might have been different if random sampling had been used, it was e qualitative data (e.g., what students wrote about how they felt about the various phenomena and whether they pursue an investigation to understand 1 them) that helped answered the research questions.

Every three weeks the students were presented with a situation/phenomenon in a short video clip and a photograph. They were told to keep a journal for a period of a whole school year (Mid October-end of April/early May) in which to write whatever they felt and thought about each situation. A total of nine situations/phenomena were given to the students. These situations/phenomena represented a variety of natural and physical phenomena, that ranged from spectacular/beautiful (e.g., the aurora borealis, a twisting somersault) and unexpected (e.g., light emitted by lamps planted in the ground/Tesla's 
experiment) or mysterious (e.g., the Namibia circles) to everyday and familiar (e.g., the behaviour of a shower curtain, the motion of ants).

It was made clear to them that it was important, for the purpose of the present study (in the form a 'home project'), that they write their 'genuine' feelings and thoughts when they first closely observed those situations/phenomena (i.e., their first reaction, their first questions) as well as their feelings and thoughts during, and at the end of, their investigation, if they really found the situations/phenomena interesting enough to pursue an investigation. The purpose of the investigation, as was also made clear to them, was to understand and explain the various phenomena, and/or to learn more about them. The students had three weeks at their disposal to investigate each situation/phenomenon and to express their feelings and thoughts about it in their journals. Their investigation could take any form (e.g., search for information on the web or elsewhere, discussion with another person, experiment if possible). The journals were anonymous, and the students could choose to drop out of the study at any time. The questions that the study attempted to answer are the following:

- How do students react to (i.e., how they feel and think about) natural and physical phenomena?

- Are there any differences between these reactions?

- Does observation of natural and physical phenomena foster a sense of wonder and engagement with science content knowledge?

- Does a wonder-at state of mind lead to a wonder-about state of mind and thus to an investigation/inquiry?

For the analysis of students' journal entries, a grounded theory approach was used (i.e., the content of the journals was scrutinized reflexively and iteratively for major emerging categories). An external researcher read through the students' journal entries and took initial notes, for the purpose of familiarizing herself with the data before the coding process began. This process focused on highlighting sentences or whole paragraphs for the purpose of creating codes that best described their content (i.e., each code described a feeling or an idea, as expressed by the student him/herself).

A constant comparative method was used to cluster the codes into more inclusive categories (Bogdan \& Biklen, 1992; Glaser \& Strauss, 1999).

It should be noted that the external researcher did an inductive thematic analysis (i.e., the initial coding of the data was not based upon a preexisting theoretical framework), without having any framework that would guide her in the process of identifying relevant concepts. In other words, the journal responses were not coded for specific characteristics of wonder, according to the literature. This was thought to be a part of this study because there was an interest to investigate how the students actually approached (i.e., feel and think about) certain situations/phenomena. At this step of the analysis, care was taken by the researcher to match relevant codes, given the high number of codes that were generated (e.g., admiration, curiosity, puzzlement, beauty, mystery, satisfaction, art/artistic creation, interest, motivation, easy or difficulty to understand, motivation to know). The next two steps involved the identification of patterns and broader categories (in order to identify themes) and the finalization of the themes. The inductive analysis resulted in three themes, namely "admiration/beauty/aesthetics", "intellectual curiosity" and "admiration/beauty mingled with intellectual curiosity". The reliability of this analysis was achieved with the use of another external researcher who checked both the codes and the coding process. That researcher checked all the material, and all codes. Given the nature of the design and the possibility of an overlap between the codes, the two researchers had to agree on all codes.

Care was taken during the final steps of the analysis to make the borders between the categories as distinct as possible, thus minimizing the overlapping between them, but this, apparently, remains one of the limitations of the study, given the nature of the experience of wonder. At the final stage, however, another step was also included to identify possible differences between entries of students from the third category (i.e., admiration/perception of beauty mingled with intellectual curiosity). More specifically, a differentiation was made between the students, whose first reaction was intellectual curiosity and after their investigation they also expressed in their journal a kind of admiration/perception of beauty, and students, whose first reaction was admiration followed by intellectual curiosity. Thus, the final categories were four, despite the great overlap between the last two. What should be noted though is that the category of intellectual curiosity includes both wonderment (aimed at comprehension) and simple curiosity (aimed at information).

In regard to the selection of the phenomena used in the study, the following points should be made. Even though anything can be a source of wonder (i.e., wonder can be evoked even by familiar and ordinary everyday entities and phenomena which, after the 
experience of wonder seem unfamiliar and extraordinary), meaning that there can be no criteria at all for selecting phenomena and entities as potential sources of wonder, for the present study the following criteria were considered: (a) phenomena that are likely to make one aware that one's knowledge is incomplete or mistaken, (b) strange, unexpected phenomena (c) beauty in nature, (d) familiar and ordinary or phenomena. While aporias are invaluable, in the sense that they foster understanding, they were not the sole criterion for selecting phenomena in this study.

For research purposes, a researcher may or may not use the same selection criteria. For it will be his/her research question that will determine the selection process. For example, he or she may wish to focus on a familiar entity like a flower, and attempt to evoke wonder in a variety of contexts. He or she may also select a phenomenon, like forces and motion, and investigate the experience of wonder, when the latter is evoked from diverse material (e.g., pictures, animation, text).

It should be pointed out that the (re)presentation of each phenomenon through a photograph (for the initial familiarization of students with a phenomenon) and a video-clip is not the same as the actual experience of phenomenon. It is very likely that a real experience in nature (e.g., observing the northern lights, a spider in its web, taking a shower and observing the movement of the curtain) may very well produce different results, especially in regard to how the students react to a phenomena and the way they express their reactions.

For teaching purposes, a teacher can certainly use the same criteria as the ones used in this study. But given that wonder is evoked, and that anything can be a source of wonder, what really matters is not so much the criteria for selecting phenomena, entities and ideas, as potential sources of wonder, as is the pedagogy a teacher will implement in his/her classroom. Such a 'pedagogy of wonder' (Hadzigeorgiou, 2016) involves questioning, in order to help students focus their attention on a phenomenon, reflection on what they see, reflection on the meaning of ideas (i.e., in the case in which an idea is a source of wonder).

\section{RESULTS AND DISCUSSION}

This section discusses the major findings of the study and is organized in four subsections, each of which focuses on a specific research question. What becomes evident though is that, depending upon the phenomenon that students observed and became involved with, wonder was experienced in two different ways, namely, as passive contemplation (i.e., aesthetic appreciation and expression of admiration of the phenomenon), and as intellectual curiosity aimed at understanding a phenomenon. Such finding provides support for a dualistic nature of the experience of wonder, which can explain why the same phenomenon can evoke either or both of these kinds of wonder in the same student. The analysis of students' journals provided support for an interplay between the two senses of wonder, which is reflected in the emerged categories.

For most of the phenomena, intellectual curiosity was in the form of wonderment (i.e., students were explicitly wondering about a phenomenon, trying to understand it). Thus, in light of the subtle difference between curiosity and wonder, intellectual (epistemic) curiosity that focused on understanding a phenomenon could be considered an experience of wonder in the form of aporia. Certainly, given that there are no other data to draw upon, one can only interpret rather than make assertions and claims about the results of the study. Thus, based solely upon what students wrote in their journals, it appears that the phenomenon which students observed/watched played a role in how they experienced a sense of wonder.

Natural/Physical Phenomena as Sources of Wonder It should be noted that the number of students, who decided to spend time to observe/watch a situation/phenomenon and/or to inquire into its origins and causes, in order to understand and/or learn more about it, varied considerably. As can be seen in Table 1, only two situations/phenomena were considered worthy of all students' attention and time to investigate. With the exception of two phenomena, namely, "Lightbulbs planted in the ground" (Nikola Tesla's famous experiment in Colorado Springs) and "The Northern Lights", some situations/phenomena were not chosen by almost half of the students of the sample, as something worthy of their attention and time (e.g., the spider's web). In fact, one situation/phenomenon was chosen by less than fifty per cent of the sample (e.g., the wandering ants). Such finding provides support for Dawkins's (1998) view about the "unaesthetic of familiarity", which is rather apparent in both the motion of ants and a spider's web. An interpretation of many students' choice not to spend time with these two phenomena is that most likely were very familiar to them, and perhaps that they did not "strike" students because of their beauty (i.e., forms, shapes, colours). Nevertheless, for some students, all nine situations/phenomena did evoke in them a sense of wonder (see Table 2). The question, therefore, that is raised here, is why those students who chose to spend time to observe/watch a 
Table 1. Number of students who decided to spend time to investigate a situation/phenomenon

\begin{tabular}{lcc}
\hline Context & Number of students & $\%$ \\
\hline The shower curtain & 29 & 63 \\
Lightbulbs planted in the ground & 46 & 100 \\
The twisting somersault & 26 & 56.5 \\
Fluorescent lamps under power lines & 37 & 80.4 \\
The Namibia circles & 34 & 73.9 \\
The Northern lights & 46 & 100 \\
The colourful stomach ants & 42 & 91.3 \\
The wandering ants & 19 & 41.3 \\
The spider's web & 24 & 52.1 \\
\hline
\end{tabular}

Table 2. Students' experience of wonder as an "emotional/cognitive reaction" to various situations/phenomena

\begin{tabular}{lllll}
\hline \multicolumn{4}{c}{ Reactions* } & \\
Context & $\mathrm{A}(\mathrm{N}=4)$ & $\mathrm{B}(\mathrm{N}=6)$ & $\mathrm{C}(\mathrm{N}=2)$ & $\mathrm{D}(\mathrm{N}=1)$ \\
\hline The shower curtain & $\mathrm{N}=4$ & $\mathrm{~N}=20$ & $\mathrm{~N}=3$ & $\mathrm{~N}=2$ \\
Lightbulbs planted in the ground & $\mathrm{N}=8$ & $\mathrm{~N}=11$ & $\mathrm{~N}=21$ & $\mathrm{~N}=6$ \\
The twisting somersault & $\mathrm{N}=10$ & $\mathrm{~N}=10$ & $\mathrm{~N}=8$ & $\mathrm{~N}=4$ \\
Fluorescent lamps under power lines & $\mathrm{N}=7$ & $\mathrm{~N}=14$ & $\mathrm{~N}=11$ & $\mathrm{~N}=5$ \\
The Namibia circles & $\mathrm{N}=6$ & $\mathrm{~N}=16$ & $\mathrm{~N}=7$ & $\mathrm{~N}=5$ \\
The Northern lights & $\mathrm{N}=13$ & $\mathrm{~N}=8$ & $\mathrm{~N}=18$ & $\mathrm{~N}=7$ \\
The colourful stomach ants & $\mathrm{N}=11$ & $\mathrm{~N}=18$ & $\mathrm{~N}=8$ & $\mathrm{~N}=5$ \\
The wandering ants & $\mathrm{N}=8$ & $\mathrm{~N}=7$ & $\mathrm{~N}=3$ & $\mathrm{~N}=1$ \\
The spider's web & $\mathrm{N}=10$ & $\mathrm{~N}=9$ & $\mathrm{~N}=3$ & $\mathrm{~N}=2$ \\
\hline
\end{tabular}

* (A): "admiration/perception of beauty", (B): "intellectual curiosity", (C) "admiration /perception of beauty followed by intellectual curiosity and admiration/perception of beauty" and (D): "intellectual curiosity followed by admiration/perception of beauty". The number of students with the same reaction across all situations/phenomena were four $(\mathrm{N}=4)$, six $(\mathrm{N}=6)$, two $(\mathrm{N}=2)$ and one $(\mathrm{N}=1)$ respectively.

phenomenon and inquire, experienced a sense of wonder at and about all situations, including those co nsidered familiar?

An interpretation of the fact that for some students all phenomena evoked in them a sense of wonder, is that those students had the opportunity to focu s their attention and observe/watch. Perhaps, they were also prepared to be receptive to what they observed/watched. If wonder can indeed be evoked by familiar and ordinary entities and phenomena (Hadzigeorgiou, 2016; Schinkel, 2020), students needed time to observe closely and attentively and to reflect. In fact, reflection is of crucial importance, and it also requires some kind of facilitation (i.e., a teacher's question, suggestion, comment). But in this study, students had no one to interact with. It was 
only a phenomenon that could make them wonder. Yet, the analysis of the content of students' journals provided some support for the possibility of wonder (see Table 2) that is both admiring/aesthetic (i.e., wonder-at state of mind) and wonder that focuses on comprehension (i.e., wonder-about state of mind). In regard to admiring wonder per se, it should be noted that all nine situations evoked in some students admiring wonder that explicitly linked beauty and knowledge of science:

I had never thought that such an amazing movement [the twisting somersault] can be so easily done by applying the principle of the conservation of angular momentum.

That nature can create all those shapes and colours with light is really incredible [...] I think it is very beautiful [..] and I realize that such beauty can be explained by means of the red and green light that oxygen atoms give off when they are excited during their collision at different heights in the atmosphere.

Certainly, the nature of the present study (i.e., the novelty of the 'home project' per se), the interest that some of the phenomena created, as well as the fact that all students were volunteers, may very well have played a role in their engagement with the study. One fact, though, remains to be considered: from the moment the students made the choice to 'take the phenomenon home' and thus observe the photo and watch the video, their attention, inadvertently, was focused on the phenomenon itself. As two students wrote:

I think that I chose the cases of the ants and shower curtain because, although these two things are not something that interest me, I thought it was the right thing to do as a participant in the study [..] I told my teacher that I would participate in the study, so I think I had to take the photos and the video-clips home. But from the moment I started to watch the situation I think I began to develop a small interest and the more I watched closely for a second time the more I realized that what I was seeing was very interesting

Although I was not interested in spiders at all, and if I have to be honest, I hated spiders [..] but I thought to watch the video-clip nonetheless. Suddenly I began to be curious about spiders. I do not know why, but perhaps it was what I was seeing, which I had not thought about before [...] it may have been those who made the video-clip that showed the things that we cannot see very often (perhaps it was a special kind of spider) [...]
My interest in spiders was greater after I read many interesting things that I did not know about, and to be honest, I did not expect that scientists have discovered all these things are things about spiders. Thus, I think I did the right thing to choose the spider video although, at first, I thought not to do so.

It deserves to be pointed out that several students (about one fourth of the sample) expressed the view that their experience (as participants in the study) was really a worthwhile one, and that such an experience could very well complement their mandated curriculum activities. And a few of them did point out that the experience of watching various phenomena made them develop a greater interest in science, something that their science lessons at school often fail to do. Based on the results of this study, once students decided to spend time to observe/watch a phenomenon they had the opportunity to observe details that are not visible to the naked eye:

I had never imagined that the diver's motion is so complicated. I knew that this kind of motion is not like the regular, the easy type of somersault, but now that I watched carefully the video-clip I could see what the diver really does. [...] I wonder if people who watch diving contests understand how complicated this kind of motion is. I think they see the whole body but not how the diver swings his arms. When I froze the screen, I took a photo with my mobile phone. The body of the diver is something fantastic".

Now that I watched the video-clip a second time, I can see that there is a rhythm in the way the ants move [...] When I looked carefully, I even saw that some ants touched other ants. I checked and saw that it happened three times in the video-clip. So, I thought that perhaps this kind of touch may be something in the world of ants [...] What I read about how ants communicate is fascinating.

\section{Differences between Students' Reactions (i.e.,} thoughts and feelings) to Phenomena

A major finding from the content analysis of students' journal entries is that their reactions and subsequent thoughts about the various situations/phenomena fell into one of the following four categories:

The "Admirers": Their reaction in general toward a situation/phenomenon is admiration, perception of beauty (wonder-at state of mind), even a bewildered curiosity but they are not intellectually curious to investigate and understand.

The "Intellectually Curious": Their sole concern is to explain, to understand, through a wonder-about 
state of mind, and a sense of aporia. For those students, admiration and beauty do not have a place in their thinking. Their curiosity aimed at both comprehension and acquisition of information.

The "True Wonderers": Their first reaction is admiration and perception of beauty, followed by a drive to understand through an investigation. Their admiration and perception of beauty (aesthetic judgement) is also expressed after they have satisfied their drive to understand.

The "Curious Admirers": Their first reaction is bewildered/intellectual curiosity, and "aporia" (puzzlement with an awareness that their knowledge is incomplete) followed by a drive to pursue an investigation in order to understand. However, after their investigation they express an admiration and amazement at the object of their investigation.

Given the considerable overlapping between the "Wonderers" and the "Curious Admirers", the differentiation between the two categories does not have any practical significance. Yet, such differentiation may have a theoretical interest, which is based on the students' first reaction to the phenomenon, and the fact that that "first reaction" was consistent across all phenomena for a few students. Nevertheless, what is important to point out is that that these two categories include students whose experience of wonder is akin to Aristotle's "thaumazein", whereas, the category "intellectual curiosity" includes those students, who were interested to understand and explain, and also learn more about a phenomenon. For according to the analysis of their journals, their entries did not include any feelings or rather words that could be associated with those feelings (e.g., amazing, astonishing, beautiful) - all the other categories include students who wondered at and/or about the various phenomena.

What becomes evident from the analysis of students' journals is that for the same student, wonder manifested itself in at least three 'guises' (i.e., categories A, B, C. D), depending on the specific phenomenon that each student approached (see table 2). However, what is also interesting to note is that a few students did experience wonder in the same way across all situations. Such finding raises a question about the possibility of a 'wonder profile'. Even though there are no data from other sources that would help enhance, through triangulation, both the credibility of the findings and their interpretation, the analysis of students' journals provides some support for "wonder profiles". One possible explanation why a few students reacted toward all phenomena in the same way might be one that considers the notion of students' worldview (see Cobern, 1996). The idea of worldview can explain, for example, the fact some students became intellectually curious about the various phenomena, while for some other students those very phenomena evoked, consistently, only feelings of admiration and aesthetic judgements, and for others a combination of both. Even though, as has already been pointed out, it is not always easy to distinguish between a curiosity and a wonderment question, there were many instances that wonder was explicit. Consider the following two questions posed by two different students: "Who would have known that the strength of a spider's web is similar to steel and the material used for making bullet-proof vests?", and "Can we say that one explanation is better than another one?", (in the case of the explanation of the motion of a shower curtain).

It could be argued, of course, that upon further questioning, those "admirers" might also had become intellectually curious. By the same token, those students, who expressed their intellectual curiosity about a phenomenon, might also had experienced a passive/contemplative wonder at the phenomenon. In other words, it is possible that some students' intellectual curiosity was more salient, compared to their admiration of a phenomenon, in their interaction with the latter, thus expressing only their intellectual curiosity. However, the consistency with which they approached all nine phenomena and the fact that they were supposed to write about their 'genuine' feelings and thoughts, points to the possibility that some students, although few, had what could be called a "profile", in regard to their experience of wonder. The fact though, according to this study and the available data, is that, for the majority of students, the experience of wonder was context-dependent (see Table 2).

It quite interesting to note that, even though those students who were categorized as "intellectually curious" could have experienced, as was pointed out above, a sense of wonder in the form of admiration mingled with intellectual curiosity as well, the fact that such sense was not explicit in their thoughts and hence in their writing, may provide support to Loren Eiseley's (1978) claim that there are two kinds of practitioners in science, namely, "the extreme reductionist who is so busy stripping things apart that the tremendous mystery has been reduced to a trifle" and the other is s/he "who still has a controlled sense of wonder before the universal mystery whether it hides in a snail's eye or within the light that impinges on that delicate organ (p. 151). Apparently, Eiseley (1978) referred to the experience of a passive/contemplative sense of wonder, which he differentiated form the curiosity of those who try to analyze everything in order to understand. Nevertheless, according to this study, 
students did experience a sense of wonder, in which admiration/aesthetic perception was present (e.g., categories A, C, and D), and which fostered investigation and understanding (except students of category A).

\section{Observation of Phenomena as a Source of Self-} Directed Inquiry

The academic benefits of self-directed (i.e., inquiry in which questions are asked by the individual) have been pointed out in the science education literature (e.g., Cacciamani, 2010; Llewellyn, 2011). This study provided evidence that natural/physical phenomena, in and of themselves, can promote self-directed inquiry. Students, while they varied in their preferences for what they found interesting and worthy of their attention and their time to search for information and investigate, did experience a sense of wonder at and about the various phenomena, and also became intellectually curious in order to learn more about them. For several students, the admiration was salient both in their response (first reaction) to a phenomenon and in their investigation. Given that the admiring/aesthetic wonder has been identified in the literature with a "passive" sense of wonder (e.g., Silverman, 1989), it is important to point out that the analysis of students' journals provided support for the fact that a 'passive' sense of wonder was also followed by a an 'active' sense of wonder, which fostered search for information and investigation (see appendix). This is an important message, and points to the crucial importance of providing students with opportunities and the time to observe and reflect, something that may not be realistic to do in the context of a science classroom where there is a schedule to be followed within a fixed time frame. While this study has no data to explain why some students did not find interesting a familiar situation/phenomenon, while others did (e.g., the movement of a shower curtain toward the running water, the movement of ants), it nevertheless provides evidence that a familiar situation/phenomenon can promote the asking of questions and further investigation for the purpose of understanding and learning more about it.

For a few students, however, passive or admiring wonder was not followed by intellectual curiosity and an investigation. This finding is very important, because it points not simply to individual differences among students, but also to the difficulties that exist when it comes to promoting self-directed inquiry in the context of science education. In fact, it points to the possibility that those few students, who consistently experienced an admiring wonder embraced an aesthetic worldview toward nature and its phenomena.

\section{Engagement with Science Content Knowledge}

The analysis of students' journals provided evidence that having the opportunity to focus on a phenomenon can 'trigger' and foster engagement with a phenomenon and thus facilitate science content knowledge acquisition. It is quite interesting to quote a student here: "My interest in spiders was greater after I read many interesting things that I did not know anything about, and to tell the truth, I did not expect that scientists have discovered all these things about spiders. [...] So, I think I did the right thing to choose the spider video, although at first I though not to do so". Even though there was no assessment of what students really learned from their participation in the present study, the fact that they did become engaged and understood several science content ideas. The following excerpts though illustrate engagement with science content (see also appendix).

Now that I looked into this phenomenon and saw that there are many explanations, I am really curious about why there are many explanations for the same phenomenon. I had never thought that that was possible. Perhaps the force that pulls the [shower] curtain in is due both to the speed of the water and to the steam. And perhaps also due to the creation of vortexes. This is a very complicated thing and I think that I need to spend more time to understand it, but I do not really know if my question why there are different explanations for the that same phenomenon will be answered. Can we say that one explanation is better than another one?

This is a puzzling phenomenon that cannot be easily explained. I thought about it and I suspect that it has to do with the different wavelengths that light contains. I noticed that the colours are never pure white but yellow, green, red, and a bit blue, I think. So, I think it has to do with some colour components of light. I will have to go online and search for this phenomenon [...] I can see, and I am satisfied, partly, because I was right that only particular colours can be observed. But it did not occur to me that that result is due to the collision of particles from the sun with oxygen and nitrogen atoms in the atmosphere, and with the Earth's magnetic field to play a part in all this.

All these things that I learned about spiders are not only unbelievable but also amazing and really fantastic (amazing). To tell the truth I checked twice perhaps three times because I did not believe all the things that I found on the internet. Who would have known that the strength of a spider's web is similar 
to steel and the material used for making bulletproof vests?

What I learned about spiders makes me think that a spider is a scientific miracle (wonder). If you think that, while almost all animals use their muscles to move around, spiders use internal fluids and the hydraulic forces that are produced. An incredible machine, that is.

\section{IMPLICATIONS FOR SCIENCE EDUCATION}

Despite the limitations of this study (due to lack of data for triangulation), its findings do point to some implications for the teaching and learning of science. Given that students developed an interest in various phenomena, even in familiar entities and phenomena (e.g., the ants, spiders motion of shower curtains) and search for information in order to understand and learn more about them, providing students with opportunities to focus their attention and observe a phenomenon should be given more serious thought in school science education. Even though what is important in science form a phenomenological perspective is the richness of sense experience (see Dahlin, 2001; Hadzigeorgiou, 2016), watching a phenomenon on a screen and thus becoming able to observe details, otherwise inaccessible to the naked eye, may very well be a worthwhile learning experience. Moreover, such an experience increases the possibilities for students to appreciate the connection between science and beauty that both evolutionary biologist Richard Dawkins and Nobel laureate physicist Richard Feynman advocated (Dawkins, 1998; Feynman, 1969, 1989).

This relationship, though, between aesthetics and science, which the present study documented in students' own experience of wonder, is of crucial importance form another perspective. While the role of wonderment in the form of intellectual/epistemic curiosity is central to science and scientific inquiry, admiring wonder (i.e., a wonder-at state of mind) before the entities and the phenomena of the natural world can both enhance the meaning students create during their interaction with those entities and phenomena, and cultivate respect for them (Hadzigeorgiou, 2014; Hadzigeorgiou \& Skoumios, 2013; Schinkel, 2017, 2020). If, in fact, learning science, and learning in general for that matter, is ultimately about a change in the way students view the world (e.g., Jardine, Clifford \& Friesen, 2003, p. 102; Pugh, 2011, p. 107; Schank, 2004, p. 37 ), then the experience of wonder should be more seriously considered, especially today that science has to play a role in the development of environmental awareness as well (e.g., Hadzigeorgiou \& Skoumios).
The finding, that a few students did not express any desire to explain scientifically and understand a phenomenon, and/or learn more about it, even though they experienced admiring/aesthetic wonder, has also implications for school science education. If this is indeed the case, then alternative approaches need to be used to introduce students to the natural phenomena and scientific knowledge. In considering the fact, that changing a student's worldview view to become compatible with the scientific worldview is not only very difficult but also morally difficult to justify (i.e., it requires substantial moral backing), an alternative way to introduce students with an aesthetic worldview toward nature to science may very well be more realistic and morally acceptable.

The fact, however, that all nine phenomena fostered engagement with content knowledge, points to the power of wonder per se to motivate students to search for information for the purpose of understanding natural and physical phenomena, and thus to the importance of complementing the mandated curriculum with activities that foster students' sense of wonder. Learning science, like all learning, is all about possibilities. The experience of wonder can no doubt increase the possibilities for an engaging experience. For as Wong (2007) has convincingly argued, our most deeply engaging experiences involve non-rational factors and a receptive stance, both of which are characteristic features of wonder: How Schinkel (2017) defines the experience of wonder should be carefully considered: "Wonder is a mode of consciousness in which we experience that which we perceive or are contemplating as in some way strange, beyond our understanding, yet worthy of our attention for its own sake, and in which our attention takes the form of an open, receptive stance".

\section{REFERENCES}

Aristotle (2002). Metaphysics. (Translated by Sachs, Joe (2nd ed.). Santa Fe, N.M.: Green Lion Press.

Ball, P. (2013). Curiosity: How science became interested in everything. Chicago: University of Chicago Press.

Bazhydai, M., \& Westermann, G. (2020). From curiosity, to wonder, to creativity: A cognitive developmental psychology perspective. In A. Schinkel (Ed.), Wonder, education, and human flourishing: Theoretical, empirical and practical perspectives (pp. 144-182). Amsterdam: VU University Press.

Bogdan, R. C., \& Biklen, S. K. (1992). Qualitative research for education: An introduction to theory and methods (2nd ed.). Boston: Allyn \& Bacon. Burnyeat, M.F. (1990). The Theaetetus of Plato (Translated by Jane Levett). Hackett. 
Cacciamani, S. (2010). Towards a knowledge building community: From guided to self-organized inquiry. Canadian Journal of Teaching and Learning, 36, 116.

Carson, R. (1965). The sense of wonder. New York: Harper \& Row Publishers.

Cobern, W. (1996). Worldview theory and conceptual change in science education. Science Education, 80, 579-610.

Dahlin, B. (2001). The primacy of cognition- or of perception? A phenomenological critique of the theoretical bases of science education. Science \& Education, 10, 453-475.

Dawkins, R (1998). Unweaving the rainbow: Science, delusion, and the appetite for wonder. New York: Teachers College Press.

De Cruz, H. (2020). Awe and wonder in scientific practice: Implications for the relationship between science and religion. In M. Fuller, D. Evers, A, Runehov, K-W.,Sæther, \& B., Michollet Eds.), Issues in Science and Theology: Nature - and Beyond (pp. 155-168). Springer.

Dewey, J. (1998). How we think. A restatement of the relation of reflective thinking to the educative process. Boston, New York: Houghton Mifflin Company. (First pubished 1910, D.C. Heath)

Drew, C., Hadrman, M., \& Hosp, J. (2008). Designing and conduting reserach in education. Los Angeles, London: SAGE Publications.

Egan, K. (2005). Students' development in theory and practice: The doubtful role of research. Harvard Educational Review, 75, 25-42.

Eiseley, L. (1978). The star thrower. New York: Times Books.

Feynman, R. (1969). What is science? The Physics Teacher 7, 313-320.

Feynman, R. (1989). What do you care what other people think? London, UK: Unwin/Hyman.

Feynman, R. (2015). The quotable Feynman. Princeton: Princeton University Press.

Gilbert, A. (2020). Pathways to wonder-infused practice: Investigating the transition from preservice to in-service teacher. In A. Schinkel (Ed.), Wonder, education, and human flourishing: Theoretical, empirical and practical perspectives (212-236). Amsterdam: VU University Press.

Gilbert, A., \& Byers, C. (2017). Wonder as a tool to engage preservice elementary teachers in science learning and teaching. Science Education, 101, 907928.

Glaser, B. G., \& Strauss, A. L. (1999). The discovery of grounded theory: Strategies for qualitative research. London, New York: Routledge.

Glăveanu, V. (2019). Creativity and wonder. The Journal of Creative Behaviour, 53, Issue 2, 171-177.

Glăveanu, V. (2020). Wonder. The extraordinary power of an ordinary experience. Bloomsbury Academic.

Hadzigeorgiou, Y. (2007). Wonder: Why is it important and how can it be evoked in the science classroom?
Paper presented at the 5th International Conference on Imagination and Education. Simon Fraser University, Vancouver, Canada, July 14-17, 2007.

Hadzigeorgiou, Y. (2012). Fostering a sense of wonder in the science classroom. Research in Science Education, 42, 985-1005.

Hadzigeorgiou, Y. (2014). Reclaiming the value of wonder in science education. In K. Egan, A. Cant, \& G. Judson (Eds.), Wonder-full education: The centrality of wonder in teaching and learning across the curriculum (pp. 40-66). New York: Routledge.

Hadzigeorgiou, Y. (2016). Imaginative science education. The central role of imagination in science education. Cham: Springer International.

Hadzigeorgiou, Y. (2020). Wonder" Its nature and its role in the learning process. In Schinkel, A. (Ed.) (2020). Wonder, education, and human flourishing: Theoretical, empirical and practical perspectives. Amsterdam: VU University Press.

https://library.oapen.org/bitstream/handle/20.50 0.12657/41804/Schinkel\%200A\%20inc\%20cover. pdf?sequence $=1$

Hadzigeorgiou, Y. \& Garganourakis, V. (2010). Using Nikola Tesla's life and experiments as presented in the film 'The Prestige' to promote scientific inquiry: A report of an action research project. Interchange, 41,363-378.

Hadzigeorgiou, Y., Prevezanou, B., Kabouropoulou, M., \& Konsolas, M. (2011). Teaching about the importance of trees. A study with young children. Environmental Education Research, 17, 519-536.

Hadzigeorgiou, Y., \& Skoumios, M. (2013). The development of environmental awareness through school science: Problems and possibilities. International Journal of Environmental \& Science Education, 8, 405-426.

Hadzigeorgiou, Y. \& Schulz, R. (2014). Romanticism and romantic science: Their contribution to science education. Science \& Education, 23, 1963-2006.

Matthews, M. (2015). Science teaching: The contribution of history and philosophy of science. New York: Routledge.

Heidegger, M. (2008). Being and time. (J. Macquarrie \& E. Robinson Trans.). New York: Harper Perennial. (Original work published 1927)

Jardine, D., Clifford, P., \& Friesen, S. (2003). Back to the basics of teaching and learning. Mahwah: Lawrence Erlbaum.

Hynes-Berry, M., \& Berry, G. (2014). "Reading an object": Developing effective scientific inquiry using student questions. European Journal of Science and Mathematics Education, 2(2), 87-97.

Kashdan, T. (2019). A new scientific framework for curiosity. Paper presented at the International Conference on Wonder, Education, and Human Flourishing, Amsterdam, Casa Hotel, April 5-6, 2019. Amsterdam, The Netherlands.

Krajcik, J., Mamlok, R., \& Hug, B. (2001). Learning science through inquiry. In L. Corno (Ed.), 
Education across a century: The centennial volume (pp. 205-238). Chicago, IL: Chicago University Press.

Krapp, A., \& Prenzel, M. (2011). Research on interest in science: Theories, methods, and findings.

International Journal of Science Education, 33(1), 27-50.

Lindhom, M. (2018). Promoting curiosity? Pitfalls and possibilities. Science \& Education, 27, 987-1002.

Llewellyn, D. (2011). Differentiated science inquiry. Thousand Oaks, CA: Corwin.

Lloyd, G. (2018). Reclaimimng wonder. After the sublime. Endiburg: Endiburg University Press.

Marcel, G. (1963). Existential background of human dignity. Cambridge: Harvard University Press.

National Research Council (1996). National science education standards. Washington, DC: AAAS

National Research Council (2007). Taking science to school. Learning and teaching science in grades $K-8$. Washington, DC: National Academic Press

Opdal, P. M. (2001). Curiosity, wonder and education seen as perspective development. Studies in Philosophy and Education, 20, 331-344.2, 435-445.

Popper, K. (1972). Objective knowledge. Oxford, UK: Clarendon Press.

Pugh, K. (2011). Transformative experience: An integrative construct in the spirit of Deweyan pragmatism. Educational Psychologist, 46, 107-121.

Riga, F., Winterbottom, M., Harris, E., \& Newby, L (2017). Inquiry-based science education. In K. Taber \& B. Akpan (Eds.), Science education: An international course companion. Springer.

Schank, R. (2004). Making minds less well educated than our own. Mahwah, NJ: Lawrence Erlbaum.

Schinkel, A. (2017). The educational importance of deep wonder. Journal of Philosophy of Education, 51, 538-553.

Schinkel, A. (Ed.) (2020). Wonder, education, and human flourishing: Theoretical, empirical and practical perspectives. Amsterdam: VU University Press.

Silverman, M. (1989). Two sides of wonder: Philosophical keys to the motivation of science learning. Synthese, 80, 43-6.

Stolberg, T. (2008). Whither the sense of wonder $f$ preservice primary teachers' when teaching science? A preliminary study of personal experience. Teaching and Teacher Education, 24, 1958-1964.

Taylor, J. (1998). Poetic knowledge. The recovery of education. New York: SUNY Press.

Tegmark, M. (2015). Our mathematical universe. UK: Penguin Books.

Whitehead, A. N. (1938). Modes of thought. New York: McMillan.

Wong, D. (2007). Beyond control and rationality: Dewey, aesthetics, motivation, and educative experiences. Teachers College Record, 109, 192220. 


\section{APPENDIX}

The Admirers: Their reaction toward the situation is admiration, perception of beauty (wonder at attitude), amazement, even a bewildered curiosity but they are not intellectually curious to understand.

Fluorescent lamps under powers lines: When I look at it, I find it very beautiful. I know it is science, physics mainly, perhaps chemistry, but it is also artistic, and I like that. Now, if you ask me to explain it, I know I have to read a lot about electricity, which, to be honest, I don't really like. To me the lamps under the powerlines are beautiful, and for me, that is the most important thing. Of course, if I had to study this phenomenon, I would certainly spend some time to learn how it works.

Light bulbs planted in the ground: What I see is something that I could not imagine. If you look at it, it seems incredible, it is amazing [...] Even though I cannot explain it I think it is very artistic. The lamps look like stars in the night sky. Very mystical and mysterious. I really like this.

The northern lights: I had never thought that light can do these things. It is incredible and beautiful. To me they look like curtains or columns of light. Really amazing. [...] I felt like being in open-air show.

The shower curtain: Now that I am thinking about it, I think that I have seen it sometimes, but it is not something that interests me. Perhaps. I am not sure, but it is not like the other situations. But it is interesting, nevertheless, if you think about it. [...] it is like a game that the water plays with the curtain [...] for me, to tell the truth, although this is interesting, I am not really interested in knowing whether there are atoms and molecules that attract each other or something else [...] if I know how to explain it what difference can that make to me? It is more interesting to see it than simply to explain it. To me this situation, I mean if I focus my eyes on the curtain and its movement toward the water, is like some kind of abstract art. Perhaps I think like that, because when I fixed my eyes on the screen, what I saw was familiar, perhaps very similar to what i had seen at art exhibition last year.

The wandering ants: Seeing them here and there they (ants) do not attract very much your attention. But when I noticed how they move, it is like they have a brain and know what they are doing and that is really amazing.

The spider web: Spiders like ants are so amazing creatures that they make you respect them [..]I am sure that if people knew all those things about spiders and ants they would not try to kill or destroy their webs.

The Intellectually Curious: Their sole concern is to explain, to understand. (wonder about attitude). For those students, admiration and beauty do not have a place in their thinking.

Fluorescent lamps under power lines: I am really thinking about how this is possible. If it is not a trick, how can we explain it? It is very strange and goes contrary to what we know about electricity. But because there are fluorescent light bulbs there must be something else. I am really curious to learn this because I like the whole thing, very clever... [...] The explanation, just like with the light bulbs that Tesla planted in the ground is very easy ...While at first you think that there is some trick some magic, with physics you can explain it very quickly.

Light bulbs planted in the ground: This is something that I could not imagine. Perhaps, if there are no hidden wires in the ground, the ground itself must have some kind of electricity, otherwise it cannot be true [...] But what I found is what I had suspected. Tesla had turned the ground into a huge battery. [...] Now it seems easy to understand.

The northern lights: Although I have heard before about this phenomenon, it is now looking at these pictures and the video clip that makes me think why it happens. It has to do with light, sure, it may be a phenomenon similar to the rainbow, something to do with the diffraction of light? Maybe yes, maybe no, I don't know. [...] I was wrong when I thought that the northern lights can be explained just like a rainbow can. The cosmic radiation as an explanation makes more sense.

The shower curtain: Looking at this phenomenon, I think that I am not sure that have noticed it. But it is very strange that it happens. Perhaps there is some kind of force between the water and the curtain. But what kind of force? I can predict it has to do with the temperature, but I am not sure. But it is something that I like to explain [...] I think I can understand it better. [...] Now that I looked into this phenomenon and saw that there are many explanations, I am really curious about why there are many explanations for the same phenomenon. I had never thought that that was possible. Perhaps the force that pulls the curtain in is due both to the speed of the water and to the steam. And perhaps also due to the creation of vortexes. This is a very complicated thing and I think that I need to spend more time to understand it, but I do not really know if my question why there are different explanations for the that same phenomenon will be answered. Can we say that one explanation is 
better than the other? [...] There may be some mistake in some of those explanations and we don't see it easily. But if we detect it, there will be just one explanation [...] Why is there only one explanation for freefall, that is, the force the earth exerts on an object, and four or more for the force exerted on the curtain? This is a question I really want to answer.

The Wandering ants: Although we see ants very often, and we can find them everywhere, now that I watch them so many questions come to mind: Where all those ants (perhaps several thousands of them) come from? Where do they go? Where were they hidden before this video-film was made? Do they communicate when they walk around? Do they have some objective or objectives to attain? These are things that I like to know plus a lot more about them [...] I have realized now that I searched for information about ants that there are so many things that I should know and the more I search the more questions I have about ants.[...] I think I could spend a whole year searching and learning about ants.

The True Wonders: Their first reaction is admiration and perception of beauty followed by a drive to understand through an investigation. Their admiration and perception of beauty is also expressed during their investigation and also after they have satisfied their drive to investigate and understand.

Fluorescent lamps under power lines: The lamps under the powerlines look amazing, and a little mysterious, but the whole thing is beautiful. But since there are no wires, it is very puzzling. But there must be an explanation [...] and I want to know it because I have never expected to have light without some kind of circuit.[. . .] Now that I can explain it I can understand it. And in the end, it is not very difficult to explain. Just an application of simple formulae. Potential difference between the ground and the pylons. And I can see there is no magic at all, there is nothing mysterious [...] It is simple physics. But it is still beautiful.

Light bulbs planted in the ground: This scene is strange and paradoxical, as if you enter another world. So magical, like in fairytales. I believe that Tesla wanted to amaze his visitors, so he developed this idea to get light from the ground. Which means an electric current through the ground. But how did he do this? This is a question that I would like to answer. [...] Very clever idea to use the ground as a source of electricity and very clever Tesla himself. [. . .] A really clever idea and an amazing result. The magic of electricity! Really what a magic, it is really amazing [...] Magic and electricity. They go together very easily.

The twisting somersault: I had never thought how amazing this kind of motion is. Watching the diver do this, you realize how much training is required to do that successfully. It is much more difficult and complex than the simple dive where the diver performs a somersault. The movement of the (diver's) arms must play a role in this complex motion.[...] I could not have thought that the twisting somersault and how it is done is based on the law of conservation of angular momentum. Such an easy explanation of such a (double), complex motion. This is really amazing [...] Really, I had never thought that such helicoid motion is the result of two separate motion. Very simple and amazing. But I think the most amazing thing is that the diver applies the laws of physics to the motion of his own body.

The northern lights: What I watched is very spectacular. Just incredible. Even though I had seen some photos of this phenomenon, I never expected that light could do so many colourful combinations. It is really beautiful [...] To me what I saw is a show that nature has created. [...] I was thinking how beautiful some phenomena like these light phenomena can be.. [...] But it is not easy to understand why this phenomenon happens. Most likely, I think, is that white light has all these colours in it. I know it happens only in places with high latitude, but why? [. ..] The explanation that I found is very simple and I like it. I liked the explanation that the colour of light formations depends on whether we have an oxygen or a nitrogen atom to collide with a particle [...]. as I see it, it is like a show, in which nature itself is both the director and the actor of the show. This is amazing, and I think all students should know about it and try to understand. But I am still wondering about the shapes that light creates, like a bird or a human face. This is amazing and I found no explanation for that.

The shower curtain: This is something amazing. I never thought that the curtain plays such a game with the running water. This is really amazing, at least to me. But before I watched the video, I could not think that such a physical phenomenon occurred. But I went to the shower myself and I did notice it [...] It is very very interesting and the force that pulls the curtain toward the water is proportional to the speed of the running water, but the question is why [...] I did not see any difference between hot and cold water, but I may be wrong. Perhaps the water was not so hot. [...] It is really very interesting that there are many hypotheses that can explain it. I had never thought that a physical phenomenon can have more than one 
explanation. This is something that makes you think that perhaps what we see is in reality many phenomena taking place simultaneously, and each hypothesis refers to each of those phenomena. But I am still wondering whether there is an explanation that includes all those hypotheses.

The wandering ants: When I was watching the video clip for some time, I realized that was something like a pattern. That pattern disappeared for a short while, but I could see it again and again. Perhaps I am wrong, but that is how I saw it. And for me this is something I did not know and did not expect to see. But it made me curious. [...] The things that I learned about ants, like most of the ants we see are females, that they are over ten thousand different species on earth, that ants have been around for millions of years (ants are as old as dinosaurs but, unlike them, they survived till our times), that they are true survivors as they lived through the ice age, are really amazing, unbelievable. What I also thought very very interesting is that ants can send out warnings when they perceive some kind of danger near them and also chemical signals (called pheremones), which are released through their body to send messages to other ants! It is incredible. [...] If people knew about such things about ants, they would certainly see them as something else, and perhaps love them the way people love flowers.

The Curious Admirers: Their first reaction is bewildered curiosity, and "aporia" (puzzlement with an awareness that their knowledge is incomplete), followed by a drive to pursue an investigation, in order to understand. However, after their investigation, they express an admiration and amazement at the object of their investigation.

Fluorescent light bulbs under power lines: I don't understand this. How can I explain it? But now that I am thinking about it, since there is light, there must be a connection somewhere, between the lamps and the power lines. But where? The photo and the video do not show any connection. Maybe there is a cable or a very thin wire at the far end in the background and we cannot see it. But it does not look like it. Very strange [...] Now that read how it works. I can understand it. It is very understandable. But if you look at it, it is fantastic! [..] You don't see this kind of thing anywhere. Without any wires you have light. This is terrific, and unbelievable and you know how it is done.

Light bulbs planted in the ground:There is something here that I have to understand. But it does not make any sense. How can you have light without any circuit? Unless there is a circuit and wires under the ground. This could easily explain the production of light. But is that really the case? [...] it was indeed a very clever idea to put electricity into the ground, thus transforming into a source of electricity, like a battery. [. . .] I think Tesla's mind was really admirable, really amazing. And the landscape he created was something different. I do not know if it is beautiful but to me is mystical and awesome. As if Tesla were a film director. The scene was really something very special. It was terrific!

The northern lights: This is a puzzling phenomenon that cannot be easily explained. I thought about it and I suspect that it has to do with the different wavelengths that light contains. I noticed that the colours are never pure white but yellow, green red, and a bit blue, I think. So I think it has to do with some colour components of light. I will have to go online and search for this phenomenon [...] I can see, and I am satisfied, partly, because I was right that only particular colours can be observed. But it did not occur to me that that result is due to the collision of particles from the sun with oxygen and nitrogen atoms in the atmosphere, and with the Earth's magnetic field to play a part in all this. An amazing thing, although the whole phenomenon looks similar to what happens in neon lights. It makes you think that light is something very simple and at the same time very complex and strange. But these strange things are beautiful and can be explained too.

The shower curtain: I think I have seen this a couple of times, but I did not pay any attention because I did not think that it was something that always happens when there is a curtain around running water. Now that I watch this video I am really puzzled. There must be a connection between the running water and the curtain. I had read that there are ions formed in the shower so I think this may explain why the curtain is pulled toward the water. But if the curtain is made from a material that does not have free electrons then how can electrical forces be produced? Now that I am thinking about it, this is a very interesting phenomenon that only physics can explain. [...] I was wrong about the explanation that I gave, but it is also amazing that there is no single explanation of this strange phenomenon. And this makes it more interesting.

The colourful-belly ants. I have never thought that there were ants with transparent stomachs. This is very interesting, and I really want to know how this is possible. Perhaps there are chemicals in their stomachs, perhaps it has something to do with their gender. But if there are so many colours, it cannot be their gender, perhaps it is their age or a combination of those things I do not know. [...] It is amazing that nature can do these kinds of things. Like nature is an 
artist. [...] I have never seen such kind of ants, and I thought that all ants were black or have a dark colour. But such a variety of colours is something unimaginable. The reason though is why. But I am sure there has to be an explanation. [...] I have not found an explanation, so I think the best explanation is that nature itself has done this. And perhaps there is a reason. Perhaps a biological reason? For evolution purposes, or something similar? I have to research for more information to explain why there are ants of that kind.

The spider's web: When I was watching the film and saw the spider build its web, one question came to my mind: how and where did spiders learn to do that? Do young spiders watch the old ones how to work and thus learn how to make their web, or is it something that they know, I mean something genetic or inherited. I do not know the answers, but that is what I really want to know [...] All these things that I learned about spiders are not only unbelievable but also amazing and really fantastic. To tell the truth I checked twice perhaps three times because I did believe all the things that I found on the internet. Who would have known that the strength of a spider's web is similar to steel and the material used for making bullet-proof vests? [...] If someone asked me what I learned from my research on spiders is that all animals have value.

What I learned about spiders makes me think that a spider is a scientific miracle (wonder). If you think that, while almost all animals use their muscles to move around, spiders use internal fluids and the hydraulic forces that are produced. An incredible machine, that is. 